Cipango Cahiers d'études japonaises

$20 \mid 2013$

Nouveaux regards sur les arts de la scène japonais I

\title{
Tout le monde, en son passé révolu... (1975)
}

\section{Yutaka Higashi}

Traducteur : Toshio Takemoto

\section{(2) OpenEdition}

\section{Journals}

Édition électronique

URL : https://journals.openedition.org/cipango/1985

DOI : 10.4000/cipango.1985

ISSN : 2260-7706

Éditeur

INALCO

Édition imprimée

Date de publication : 30 octobre 2013

ISSN : 1164-5857

\section{Référence électronique}

Yutaka Higashi, «Tout le monde, en son passé révolu... (1975) », Cipango [En ligne], 20 | 2013, mis en ligne le 17 avril 2015, consulté le 30 juin 2021. URL : http://journals.openedition.org/cipango/1985 ; DOI : https://doi.org/10.4000/cipango.1985

Ce document a été généré automatiquement le 30 juin 2021.

\section{(c) (1) \$}

Cipango est mis à disposition selon les termes de la Licence Creative Commons Attribution - Pas d'Utilisation Commerciale 4.0 International. 


\title{
Tout le monde, en son passé révolu... (1975)
}

\author{
Yutaka Higashi \\ Traduction : Toshio Takemoto
}

\section{NOTE DE L'AUTEUR}

HIGASHI Yutaka 東由多加, «Hito wa daremo sugisatta kakoni 人は誰も過ぎ去った過去 に», in Higashi Yutaka ga nokoshita kotoba 東由多加が遺した言葉 Mots laissés par Higashi Yutaka), Tōkyō, Jiritsu shobō 而立書房, 2002, p. 44-45.

1 J'ai eu trente ans. Deux jours plus tard, je croise mon ami Akita Meidai dans un bar de Shibuya. Son visage brun et son élocution difficile du fait de l'alcool, et puis mon visage pâle et la vacuité de mon éloquence. Tout en buvant avec lui, j'ai fini par revenir au passé. À l'époque des «Flower Children ", à laquelle j'ai dit adieu. Akita m'a dit passer cinq jours par semaine dans des baraques d'ouvriers, et un jour à jouer au rugby sur un stade au bord de la rivière Tamagawa. Le jour d'après, sous un soleil inattendu de printemps, tandis que je flânais sur la rive de la Tamagawa, pris par l'envie de le voir jouer au rugby, je suis encore revenu sur le passé. Ça n'accroît pas ma colère, c'est juste « de l'agacement et de l'hésitation ».

2 Je parle au public des comédies musicales des Tōkyō Kid Brothers, puis aux gens qui nous ont encouragés, aux spectateurs qui sont venus voir "Octobre, patrie de pénombre $»^{1}$. Notre spectacle ne visait pas «le respect de la convention théâtrale ", mais notre amour de « la jeunesse ». Nous avons tenté de faire de cet instant une image fixe, de lancer un appel en direction de ce moment crucial qui se dérobe au photographe. C'était absolument ce sur quoi il semblait impossible de revenir : «Faire feu en direction de demain ». Nous vivions ensemble, c'était une sorte de "théâtre ", une sorte de "chanson", nous disions juste que nous en sommes venus à vivre ensemble. Au théâtre, avec des inconnus, nous avons voulu fixer cet instant avec les 
yeux du cœur. Cette fois, notre comédie musicale, assurément pleine de sentimentalisme, me semble dévoiler mon passé sans vergogne aucune.

3 Les mots d'un pilote de rallye automobile, décédé l'année dernière, m'ont ému : "Je veux vivre pleinement cette vie qui ne m'est donnée qu'une seule fois. De toutes mes forces... Moi, au lieu de vivre une vie au compte-gouttes, je veux passer une vie pleine et forte. Et si, en plus, je pouvais vivre longtemps, ce serait magnifique !»

4 En flânant au bord de la Tamagawa, je me disais : même si nous ne faisions que vivre longuement et vainement, dans le désœuvrement, cherchant à avoir une longue vie au détriment du reste, nous devrions tout de même rejeter notre passé. Si nous ne parvenions pas à "tirer une flèche vers demain", cette œuvre serait au Japon la dernière comédie musicale des Tōkyō Kid Brothers. Au cri de : «Ne vous fiez pas aux hommes de plus de trente ans! » Pourtant cela ne fait aucun doute : nul ne peut voir le for intérieur des hommes qui ont passé les trente ans. À présent, j'ignore ce que devient le théâtre. Pour moi, ça signifiait une sorte de « lutte pour l'amour ».

Tous les hommes, dans les jours révolus,

oublient qu'ils ont laissé l'amour quelque part.

\section{NOTES}

1. YOMIURI hōlu 読売ホール, Yūbinchokin hōlu 郵便貯金ホール, juin-juillet 1975. Ces deux représentations à Tōkyō ont été suivies d'une tournée au Japon. 